action between thymic lymphocytes and thyroid antigen stimulating B-lymphocytes and H.T.S.I. production, ${ }^{27}$ or a reduction in the controlling $\mathrm{T}$-lymphocyte population leading to increased autoantibody formation by the B cells. ${ }^{28}$ The latter view seems most likely in the light of present knowledge, but perhaps it is safer to describe the underlying abnormality with the fashionable and anodyne phrase ${ }^{29}$ "failure of immunological surveillance."

1 Adams, D. D., and Purves, H. D., Proceedings University of Otago Medical

School, 1956, 34, 11.
2 Kriss, J. P., Pleshakov, V., and Chian, J. R., fournal of Clinical Endocrinology, 1964, 24, 1005.

3 Kriss, J. P., fournal of Clinical Endocrinology, 1968, 28, 1440.

${ }^{3}$ Kriss, J. P., Fournal of Clinical Endocrinology, 1968, 28, 1440. and Clinical Medicine, 1967, 70, 640.

5 Beall, G. N., and Solomon, D. H., Fournal of Clinical Endocrinology, $1968,28,503$.

6 Beall, G. N., et al., Fournal of Laboratory and Clinical Medicine, 1969,

${ }^{7}$ Chopra, I. J., Beall, G. N., and Solomon, D. H., fournal of Clinical Endocrinology, 1971, 32, 772.

${ }^{8}$ Dirmikis, S., and Munro, D. S., Fournal of Endocrinology, 1973, 58, 577.

${ }^{9}$ Dirmikis, S., Fournal of Endocrinology, 1974, 63, 427.

10 McKenzie, J. M., Physiological Reviews, 1968, 48, 252.

11 Chopra, I. J., Solomon, D. H., and Limberg, N. P., Fournal of Clinical Endocrinology, 1970, 31, 382.

12 Carneiro, L., Dorrington, K. J., and Munro, D. S., Lancet, 1966, 2, 878. 13 Chopra, I. J., et al., Metabolism, 1970, 19, 760.

14 Lipman, L. M., et al., American fournal of Medicine, 1967, 43, 486.

15 Chopra, I. J., and Solomon, D. H., Annals of Internal Medicine, 1970, 73, 985 .

${ }^{16}$ Adams, D. D., and Kennedy, T. H., Fournal of Clinical Endocrinology 1967, 27, 173.

17 Shishiba, Y., et al., fournal of Clinical Endocrinology, 1973, 36, 517.

18 Adams, D. D., Proceedings Fifth Asia and Oceania Congress of Endocrinology, 1974, 2, 55.

${ }^{1}$ Adams, D. D., and Kennedy, T. H., fournal of Clinical Endocrinology, $1971,33,47$.

20 Adams, D. D., Kennedy, T. H., and Stewart, R. D. H., British Medical fournal, 1974, 2, 199

21 Nutt, J., et al., British Medical fournal, 1974, 4, 695.

22 Mehdi, S. Q., et al., Biochemical Society Transactions, 1973, 1, 1005.

23 Smith, B. R., and Hall, R., Lancet, 1974, 2, 427

24 Mukhtar, E. D., et al., Lancet, 1975, 1, 713.

26 Volpe, R., et al., Clinical Endocrinology, 1974, 3, 239.

27 Lamki, L., Row, V. V., and Volpe, R., fournal of Clinical Endocrinology, $1973,36,358$.

${ }^{28}$ Irvine, W. J., Proceedings Royal Society of Medicine, 1974, 67, 548.

29 Hoffenberg, R., British Medical Fournal, 1974, 3, 508.

\section{Pregnancy with an Intrauterine Contraceptive Device}

For ten years now it has been known that when a woman with an intrauterine contraceptive device in situ becomes pregnant she runs a high risk of spontaneous abortion and that about 1 in 5 of the pregnancies will be ectopic. ${ }^{1-3}$ In the U.S.A. additional concern has centred on the possible association of infection in the pregnant uterus with the Dalkon Shield device; 209 septic abortions and 11 maternal deaths have been imputed to its presence. ${ }^{4}$ Tatum and his colleagues ${ }^{5}$ have recently emphasized that the tail of this device is structurally and functionally different from the monofilament tails of four others-the Lippes loop, Saf-T-Coil, Copper 7, and Copper T. They concluded from their experiments that the unique characteristics of the polyfilament Dalkon tail could provide a mechanism whereby pathogenic organisms could ascend from the vagina to infect the uterine cavity. Infection would be more likely and more serious if the Shield were not removed before the 8-10th week of pregnancy, after which time the whole of the tail would be drawn up inside the uterus. Certainly most of the serious infections reported have occurred in the second trimester of pregnancy.
Also in the U.S.A. Dreishpoon detailed 31 pregnancies with intrauterine devices in situ but none of them Dalkon Shields. ${ }^{6}$ Four of the pregnancies were ectopic, 15 ended in abortion, and only 7 were uncomplicated and full-time. In the end there were 10 "take-home" babies, but he was so impressed by the high rates of abortion, sepsis, and haemorrhage that he advised that early termination of pregnancy be performed if there were an intrauterine device present.

On this side of the Atlantic Steven and Fraser ${ }^{7}$ have reviewed 82 pregnancies with devices in the uterus. Four of the pregnancies were ectopic, a usual proportion, and 24 were terminated legally. Of the remaining 54, 31 ended in spontaneous abortion, more than half of these in the second trimester. Even among the 23 viable pregnancies the complication rate was high: haemorrhage, ante- or post-partum, in $13 \%$, and manual removal of the placenta in $17 \%$. These results led the authors to suggest that an intrauterine device might not only stimulate the pregnant uterus to excessive contractions but also affect the attachment to the placenta to the uterine wall. Nevertheless, 22 of the 23 babies survived, and though the device was a Dalkon Shield in 30 of the 82 patients sepsis occurred in only one, where the type was not specified.

It seems reasonable to conclude that, while reservations about the use of the Dalkon Shield with its polyfilament tail will continue, every woman should be warned emphatically at the time of insertion of any intrauterine device that sheshould report at once whenever a period is two weeks overdue. If pregnancy is then confirmed the device should be removed while the tail is still accessible vaginally, and the question of termination of the pregnancy discussed with the patient in accordance with the circumstances of her individual case.

1 Teitze, C., American fournal of Obstetrics and Gynecology, 1966, 96, 1043. 2 Lewit, S., Contraception, 1970, 2, 47.

3 Portnuff, J. C., et al., American fournal of Obstetrics and Gynecology, 1972, $114,934$.

${ }^{4}$ Culliton, B. J., and Knopman, D. S., Science, 1974, 185, 839.

5 Tatum, H. J., et al., Fournal of the American Medical Association, 1975,

231, 711.
6 Dreishpoon, I. H., American.Fournal of Obstetrics and Gynecology, 1975,

7 121, 412. the British Commonwealth, 1974, 81, 282.

\section{Response to Stress and Ulcers}

Psychosomatic research into the pathogenesis of peptic ulcer has been dominated for far too long by the grand generalizations of a generation ago. The simple and seductive theories then in play suggested that certain people - the ambitious, the striving, and the go-getters according to Alvarez ${ }^{1}$ and to Dunbar $^{2}$ or, according to Alexander, ${ }^{3}$ people with unconscious conflicts about dependence-were ulcer-prone. This susceptibility culminated in ulceration or a relapse if these individuals were exposed to emotional stress. The effect of emotion on the mucosa of the stomach had already been amply shown in the cases of Alexis St. Martin ${ }^{4}$ and of "Tom." 5

But since then many studies ${ }^{6-9}$ have made it clear that both personality-type and specific conflict are inadequate and weak indicators of individual susceptibility. Those, moreover, who would incriminate the stress of modern life in precipitation have had to accommodate themselves to the falling incidence ${ }^{10}$ 
of peptic ulcer and a falling death rate, ${ }^{11}$ which are unlikely to be due to improvements in treatment.

A major advance in defining susceptibility more rigorously was the discovery by Mirsky and his colleagues ${ }^{12}$ of the predictive value of the plasma pepsinogen level. In $87 \%$ of patients with duodenal ulcer the plasma pepsinogen concentration is greater than the mean of values found in people without gastrointestinal disturbance. This observation is consistent with the view that patients with duodenal ulcer secrete more gastric juice, more acid, and more pepsin than do healthy people. The $14 \%$ with high plasma pepsinogen levels but no history of indigestion are presumably at risk. Using plasma pepsinogen values and psychological testing to identify those with "oral cravings and conflicts" (an extension of Alexander's hypothesis), Weiner, Mirsky, and others ${ }^{13}$ had some success in predicting ulceration in U.S. Army recruits under the stress of basic training.

Nevertheless, the most stimulating work on individual susceptibility to ulceration comes from studies of the effects of immobilization in rats. Extending the original French work ${ }^{1415}$ on constraint and immobilization as a technique for producing ulcers, Ader and his colleagues ${ }^{16}$ at the University of Rochester in New York have defined the conditions in the present and the past that favour ulceration in laboratory rats. A useful summary of this work by Engel has appeared recently. ${ }^{17}$

Almost every rat, it seems, if deprived of food and water and confined in a cage $200 \mathrm{~cm}^{3}$ in volume or less will develop stomach erosions within 24 hours. Less tight confinement for shorter periods allows individual differences in susceptibility, such as the effect of a high plasma pepsinogen level, to appear. Rats were more susceptible if immobilized at night, their active time, rather than in the daytime; if they had been reared in a group rather than alone; if not handled in the preweaning period; or if the mother had been handled while pregnant. Moreover, as Engel points out, these differences in prenatal, postnatal, and current experience may produce an increase or a decrease in susceptibility to a wide variety of other diseases-infections, tumours, or metabolic disorders.

In a further series of experiments Weiss ${ }^{18}$ has shown that rats which are immobilized and given electric shocks will develop more ulceration than those which are not shocked. If, however, an immobilized rat is able to learn from a warning signal that pressure on a panel will avert the shock it will develop far less ulceration than its fellow which had no switch, can do nothing to help itself, and gives up.

It may well be true that ulceration in rats bears only the most superficial resemblance to human peptic ulcer. The equivalents of handling and immobilization within human experience are obscure and cannot be soundly based on crude analogy. But ulceration in the rat in such psychosocial conditions is certainly psychosomatic, and if this research shows nothing else of relevance to disease in man it at least demonstrates complexity: the complexity of past experience in determining susceptibility to disease and the complexity underlying the perception of current experience as stressful.

Engel contends that one important factor contributing to lowered resistance to disease is the loss of the organism's ability to predict and maintain control over its environment. The consequent "fruitless activity" or alternatively" giving up"-adapting Sherrington, he calls these final common paths -may "interact differently with different pathogenic preconditions, and hence constitute variables underlying differential susceptibility to disease in different individuals." For one person with a background of specific genetic influences and life experiences giving up may be more pathogenic; for another or in a different disease process fruitless struggle may be more characteristic and yet more harmful. We have come a long way from the simplicities of go-getters, muddlers, and top dogs.

1 Alvarez, W. C., Nervousness, Indigestion and Pain. Harper, New York, 1943.

2 Dunbar, F., Psychomatic Diagnosis. Hoeber, New York, 1943.

3 Alexander, F., Psychosomatic Medicine. Norton, New York, 1950.

Beaumont, W., Experiments and Observations on the Gastric fuice and in the Physiology of Digestion, ed. A. Combe. Edinburgh, MacLachlan and Stewart, 1838 .

${ }^{5}$ Wolf, S., and Wolfe, H. G., Human Gastric Function: an Experimental Study of a Man and his Stomach. New York, Oxford, 1947.

6 Mahl, G. F., Psychosomatic Medicine, 1950, 12, 158.

7 Kellock, T. D., British Medical Fournal, 1951, 2, 1117.

de M'Uzan, M., and Bonfils, S., Revue Française d'Etudes Cliniques et Biologiques, 1961, 6, 46.

10 Meade, T. W., et al., British Medical Fournal, 1968, 3, 701.

The Registrar General's Statistical Review of England and Wales. 1966. Part III. Commentary. London, H.M.S.O., 1968.

12 Mirsky, I. A., Futterman, P., and Kaplan, S., Fournal of Clinical Medicine, $1952,40,188$.

13 Weiner, H., et al., Psychosomatic Medicine, 1957, 19, 1.

14 Rossi, G., et al., Comptes Rendus de la Société de Biologie, 1956, 150, 2124.

15 Bonfils, F., et al., Comptes Rerdus de la Société de Biologie, 1957, 151, 1149.

16 Ader, R., Advances in Psychosomatic Medicine, Vol. 6, 1971, p. 1.

17 Engel, G. L., Gastroenterology, 1974, 67, 1085.

18 Weiss, J. M., in Physiology, Emotion and Psychosomatic Illness, ed. R. Porter and J. Knight. Amsterdam, Elsevier-Excerpta Medica, 1972.

\section{Do Little Bellyachers Grow Up to Become Big Bellyachers?}

Recurrent abdominal pain occurs in one out of every nine schoolchildren. ${ }^{1}$ An organic cause for the pain is found in about $7 \%$, so that for the great majority the doctor is left telling the parents that there is no serious cause; he usually goes on to assure them that the child will grow out of the problem. However, as Apley ${ }^{2}$ pointed out, the children with recurrent abdominal pains tend as a group to be more timid, anxious, tense, and fussy than those who are symptom free; they also tend to be over-conscientious and to be bad mixers. In some there is a clear link between abdominal symptoms and specific emotional disturbances, ${ }^{3}$ so that many doctors have worried about the future lives of these children, and the more resourceful have investigated them.

A number of good follow-up studies of children with this syndrome have been completed. Three outcomes are possible for these children as adults, some 10 to 20 years later: they may still have abdominal symptoms; or they may have different "nervous" complaints such as headaches and migraine; or they may be completely free of symptoms. The earlier studies ${ }^{24}$ suggested that children with recurrent abdominal pain were fairly evenly divided among the three groups as adults, though one report ${ }^{5}$ suggested that half became symptom free. More recent work from Denmark presents a gloomier picture. ${ }^{6}$

Thirty-eight children with a mean age of 8 years diagnosed as having recurrent abdominal pain in the years 1942-3 were studied. The diagnosis was made on the basis of at least three episodes of abdominal pain occurring in a period of longer than three months. All the children were fully investigated to exclude organic cause. Thirty years later they were traced as adults, interviewed, and if necessary examined and investigated. The 34 adults traced had a mean age of 36 years. Eighteen had troublesome abdominal symptoms: 11 were considered to have irritable colon, 5 irritable colon plus peptic ulcer, and 2 a definite duodenal ulcer. This incidence 